\title{
Quantitative analyses of relationships between ecotoxicological effects and combined pollution
}

\author{
ZHOU Qixing, CHENG Yun, ZHANG Qianru \& LIANG Jidong \\ Key Laboratory of Terrestrial Ecological Process, Institute of Applied Ecology, Chinese Academy of Sciences, Shenyang 110016, China \\ Correspondence should be addressed to Zhou Qixing (email: Zhouq@mail.sy.In.cn or Zhouqixing2003@yahoo.com)
}

Received September 9, 2003

\begin{abstract}
The responses of wheat Triticum aestivum, rice Oryza sativa, earthworms Eisenia foetida, and prawns Penaeus japonicus to combined acetochlor-Cu, Cd-Zn were studied in hydroponic and soil-culturing systems using the methods of ecotoxicology. In particular, systematically quantitative analyses were documented by field experiments. Results showed that ecotoxicological effects under the combined pollution were not only related to chemical properties of pollutants but also dependent on the concentration level of pollutants, in particular on the combination of concentrations of pollutants in ecosystems. Additionally, species of organisms, especially the type of ecosystem, determined the influences. To some extent, biological tissue targets attacked by pollutants were an important factor.
\end{abstract}

Keywords: combined pollution, ecotoxicological effect, pollutant, biological toxicity, quantitative analysis.

DOI: 10.1360/03yc0042

In 1939, Bliss first defined the toxicity of poisons applied jointly by "antagonism, synergism, addition and dependent action". He thought that this kind of joint effects were only subject to their natural chemical properties ${ }^{[1]}$. With the increasing categories and quantities of contaminants released into the environment since the $1970 \mathrm{~s}^{[2,3]}$, effects of combined contamination and the interactions between pollutants have been increasingly seen as a source of concern ${ }^{[4-7]}$. Besides the regularly tested animals such as rats, rabbits, guinea pigs, frogs and dogs used in the early toxicological studies, aqueous organisms including fish and algae, some crops, rice and wheat for example, even soil animals and soil microbes have been used to investigate the ecotoxicity of pollutants. Indexes of toxic effect evaluation, the extent of toxicity or $\mathrm{IC}_{50}$, and the effects on the production and toxin-accumulation in bodies have been extensively studied ${ }^{[7-10]}$.
Many studies have helped develop the widely accepted conclusion that the ecotoxicological effects of combined contamination were determined by not only the chemical properties of pollutants or toxic elements, but also by the concentration level ${ }^{[11,12]}$. However, a few observations have recently revealed that the concept must be improved and corrected because of significant limitations.

\section{Materials and methods}

\subsection{In-vivo soil culture toxicity test}

In this part, wheat Triticum aestivum was selected as the living organism for the toxicity test. The tested pollutants included a herbicide in common use, 50\% of oil soluble concentration of acetochlor $\left(\mathrm{C}_{14} \mathrm{H}_{20^{-}}\right.$ $\mathrm{ClNO}_{2}$ ) which was provided by the Ruize Pesticide Limited Co. Dalian, and $\mathrm{CuSO}_{4} \cdot 5 \mathrm{H}_{2} \mathrm{O}$ (analytic grade), bought from the Third Reagent Factory Shen- 
yang. Based on the previous combined pollution experiments $^{[7]}$, the dose of acetochlor exposed to wheat was $0,0.1,0.3,0.6,0.9,1.2$, and $1.5 \mathrm{mg} / \mathrm{kg}$, and that of copper $(\mathrm{Cu})$ was 30,90 , and $150 \mathrm{mg} / \mathrm{kg}$.

After being mixed with the above various doses of $\mathrm{Cu}$ and acetochlor, the air-dried soil samples collected from a field in the Hailun Station of Agricultural Ecology, Heilongjiang Province were put in pots overnight and irrigated with $200 \mathrm{~mL}$ of tap water. All treatments were replicated 4 times, and each replicate consisted of $4 \mathrm{~kg}$ soil and 5 seedlings of wheat. They were moistened using $200 \mathrm{~mL}$ of tap water every 3 days. Once mature, fruits were harvested, washed, air-dried and weighed. Roots and fronds were separately harvested, washed, air-dried and ground by machine. The ground samples were then analyzed for the total concentration of $\mathrm{Cu}$ using the atomic absorption spectrophotometer after a digestion in concentrated $\mathrm{HNO}_{3}-\mathrm{HClO}_{4}$ solution.

\subsection{In-vivo water culture toxicity test}

Rice Oryza sativa was selected for the hydroponic experiments. The tested pollutants were $\mathrm{ZnSO}_{4} \cdot 7 \mathrm{H}_{2} \mathrm{O}$ and $\mathrm{CdCl}_{2} \cdot(5 / 2) \mathrm{H}_{2} \mathrm{O}$. On the basis of the previous experimental results ${ }^{[13]}$, the concentration of $\mathrm{Cd}$ exposed to rice plants was $0,1,1.5,3.0$, and 6.0 $\mathrm{mg} / \mathrm{L}$, and that of $\mathrm{Zn}$ was 100,200 , and $300 \mathrm{mg} / \mathrm{L}$.

Four kilograms of air-dried black soils were completely mixed with 1.5 liters of tap water and allowed to stand for $5 \mathrm{~min}$. After being mixed with the above various concentrations of $\mathrm{Zn}$ and $\mathrm{Cd}, 1$ liter of suspension liquid was put in a plastic bucket. Each bucket consisted of 5 seedlings of rice fixed with sponge and plastic ropes. All treatments were replicated 4 times. $400 \mathrm{~mL}$ tap water was added every 3 days. Once mature, fruits were harvested, washed, air-dried and weighed. Roots and fronds were separately harvested, washed, air-dried and ground with a machine. The ground samples were then analyzed for the total concentration of zinc using the atomic absorption spectrophotometer after a digestion in concentrated $\mathrm{HNO}_{3}-\mathrm{HClO}_{4}$ solution.

\subsection{In-vitro terrestrial ecotoxicity test}

The earthworm Eisenia foetida, the tested organism living in soil, was used as an international standard for ecotoxicological experiments. Before the formal experiments, healthy and mature E. foetida with weight ranging from 300 to $500 \mathrm{mg}$ and with a similar size of band were precultivated to determine the MLD and $\mathrm{LD}_{100}$, namely the minimum and $100 \%$ lethal dose after a 48-h exposure. Within the range between the MLD and $\mathrm{LD}_{100}$, the dose of acetochlor was set to $0,0.1,0.2,0.3,0.4,0.5$, and $0.6 \mathrm{mg} / \mathrm{kg}$, and that of $\mathrm{Cu}$ was $30,60,90,120$, and $150 \mathrm{mg} / \mathrm{kg}$ for the single pollution experiments. Based on the single factor investigations, two levels of copper $(30 \mathrm{mg} / \mathrm{kg}$ and $90 \mathrm{mg} / \mathrm{kg}$ ) were mixed with the above doses of acetochlor.

The in-vitro experiment for toxicity followed the below procedures: E. foetida were washed and put to beakers with water to merge half bodies after precultivation. The beakers were then sealed with a thin plastic film with numerous tiny holes punctured by a needle, and finally cultivated in a biochemical incubator at $20 \pm 1^{\circ} \mathrm{C}$ overnight to clean the intestines. After precultivation, $15 \mathrm{E}$. foetida were washed, toweled off with filter paper, and put in a Petri dish with $10 \mathrm{~mL}$ of acetochlor and $\mathrm{CuSO}_{4}$ at the designed level with 5 pieces of filter paper laid at the bottom. In order to prevent the worms from escaping, the Petri dishes were sealed with gauze; they were then placed in a dark incubator at $20 \pm 1{ }^{\circ} \mathrm{C}$ for $48 \mathrm{~h}$. All the treatments were replicated 3 times. The toxicological symptoms and actions were recorded periodically. If the tail was insensitive to mechanical incentives, E. foetida was considered dead. The number of dead E. foetida was recorded after 24-h and 48-h exposure for the statistic analyses.

\subsection{In-vitro aquatic ecotoxicity test}

The tested prawn Penaeus japonicus was collected from the Zhoushan seawater, Zhejiang Province. Before the formal experiments, healthy and mature $P$. japonicus with a similar size and weight ranging from 5 to $6 \mathrm{~g}$ were precultivated to determine the concentra- 
tion range under single contamination. The dose of acetochlor exposed to the prawns was $0,0.04,0.08$, $0.12,0.16,0.20$, and $0.24 \mathrm{mg} / \mathrm{kg}$, and that of $\mathrm{Cu}$ was $30,45,60,75$, and $90 \mathrm{mg} / \mathrm{kg}$. Based on the single factor investigations, two levels of copper $(30 \mathrm{mg} / \mathrm{kg}$ and $90 \mathrm{mg} / \mathrm{kg}$ ) were mixed with the above doses of acetochlor.

The in-vitro experiment for toxicity followed the below procedures: $P$. japonicus were washed with seawater and put in 1 liter beakers with $600 \mathrm{~mL}$ seawater and the above various doses of pollutants. $10 \mathrm{P}$. japonicus were put in one beaker and aerated vigorously. All the treatments were replicated 3 times. The toxicological symptoms and actions were recorded periodically. If the tail was insensitive to mechanical incentives, $P$. japonicus was considered dead. The number of dead $P$. japonicus was recorded after 24-h and 48-h exposure for the statistic analyses.

\subsection{DGGE fingerprinting analysis}

Tested phaeozem (black soil) samples for DGGE analysis were also collected from the Hailun Station of Agricultural Ecology, Heilongjiang Province. The background concentrations of acetochlor and $\mathrm{Cu}$ in the clean soil from a clean field without any pesticide application for more than a decade were 0.8 and 21.3 $\mathrm{mg} / \mathrm{kg}$, respectively. Concentrations of acetochlor and $\mathrm{Cu}$ in the polluted soil from a polluted field to which acetochlor and germicide containing $\mathrm{Cu}$ have been heavily applied for many years were 91.7 and 83.2 $\mathrm{mg} / \mathrm{kg}$, respectively. Tested pollutants were the same as those in sections 1.1, 1.3 and 1.4. Fresh clean soil samples were equably mixed and ground to pass through a sieve with $0.2 \mathrm{~mm}$ openings. Acetochlor and $\mathrm{Cu}$ were added to plastic bottles filled with $150 \mathrm{~g}$ of ground soil samples. According to the pre-experimental results, the concentration of acetochlor added to the soils was 0,100 , and $250 \mathrm{mg} / \mathrm{kg}$, and that of $\mathrm{Cu}$ was 0,100 and $300 \mathrm{mg} / \mathrm{kg}$. Having been sealed, the bottles were stored in a constant-temperature incubating box at $20^{\circ} \mathrm{C}$. In other words, soil microorganisms in the bottles were exposed to single-factor and combined pollution. All the treatments were replicated 3 times. Total soil-microbial DNA was extracted based on the method suggested by Martin-Laurent et al. ${ }^{[13]}$. The purification of extracted DNA was carried out according to the instructions for DNA gel reclamation in a silver-bead reagent box (made in Shanghai).

Nest-PCR cloning based on the Thermo Hybaid PCR express cloning vector was used. Reaction I (50 $\mu \mathrm{L}$ ) was: $5 \mu \mathrm{L}$ of $10 \times$ Buffer, $4 \mu \mathrm{L}$ of $2.5 \mathrm{mmol} / \mathrm{L}$ dNTP, $4 \mu \mathrm{L}$ of $10 \mathrm{pmol} / \mu \mathrm{L}$ primers F8-27f, $4 \mu \mathrm{L}$ of 10 $\mathrm{pmol} / \mu \mathrm{L}$ primers $1541-1522 \mathrm{r}, 1 \mu \mathrm{L}$ templet DNA, $0.1 \mu \mathrm{L}$ of $5 \mathrm{U} / \mu \mathrm{L}$ Ex Taq enzyme (Dalian Bao Bio. Co.), $31.9 \mu \mathrm{L}$ hyperpure water. There were 16 cycles in the reaction: $95^{\circ} \mathrm{C}(5 \mathrm{~min}), 1$ cycle; $95^{\circ} \mathrm{C}(1 \mathrm{~min})$, $62^{\circ} \mathrm{C}(1 \mathrm{~min})$, and $72^{\circ} \mathrm{C}(3 \mathrm{~min}), 15$ cycles. Reaction II was basically the same as reaction I, but the primers were P338f-GC and P518r, model DNA was $3 \mu \mathrm{L}$ of products from reaction I, and $29.9 \mu \mathrm{L}$ hyperpure water. There were 36 cycles in reaction II: $94^{\circ} \mathrm{C}(1 \mathrm{~min})$, $60^{\circ} \mathrm{C}(30 \mathrm{~s})$, and $72^{\circ} \mathrm{C}(2 \mathrm{~min}), 10$ cycles; $94^{\circ} \mathrm{C}(30$ $\mathrm{s}), 60-55^{\circ} \mathrm{C}(30 \mathrm{~s})\left(0.5^{\circ} \mathrm{C}\right.$ was decreased at a cycle), and $72^{\circ} \mathrm{C}(2 \mathrm{~min}), 10$ cycles; $94^{\circ} \mathrm{C}(30 \mathrm{~s}), 55^{\circ} \mathrm{C}(30$ s), and $72^{\circ} \mathrm{C}(2 \mathrm{~min}), 15$ cycles; $72^{\circ} \mathrm{C}$ was extended to 8 min after 35 cycles.

Two groups of PCR amplified primers were used. The first primers (the general bacterium primers): the forward primer P8-27F (5'AGAGTTTGATCMTGG$\mathrm{CTCAG}^{\prime}, \mathrm{M}$ is $\mathrm{A}$ or $\mathrm{C}$ ) and the reverse primer P1541-1522R (5'AAGGAGGTGATCCAGCCGCA $\left.3^{\prime}\right)^{[14]}$; the second primers (primers for analysis of bacterium communities): the forward primer P338f ( $5^{\prime}$ ACTCCTACGGGAGGCAGCAG3') and the reverse primer P518r (5'ATTACCGCGGCTGCTGG3'). In order to avoid conglutination of amplified segments, the GC clamp (5'CGCCCGCCGCGCGCGGCGGGCGGGGCGGGGGCACGGGGGG3' $)^{[15]}$ was linked with the forward primers.

PCR products were analyzed on denaturing gradient gel electrophoresis (DGGE) gels by using the Dcode system electrophoresis apparatus (from the Bio-Rad Co.) method based on the protocol of Muyzer and co-workers ${ }^{[16]}$. After the DGGE analysis, silver 
staining of DNA was undertaken based on the modified method suggested by Bassam and Caetano-Anollés $(1991)^{[17]}$. DGGE fingerprinting analysis and bands were identified using the gel imaging system (the Bio-Rad Co.).

\subsection{In-situ quantificational analysis}

In order to determine the effects of combined pollution on $\mathrm{Cd}$ and $\mathrm{Zn}$ accumulation in crops, potato (Solanum tuberosum), Chinese cabbage (Brassica Pekinensis Rupr), and wild amaranth (Amaranthus retroflexus) were collected from the Zhangshi Sewage-Irrigation area, and the Qingchengzi Lead-Zinc mining region. Those from the uncontaminated Shilihe area were used as the control.

\subsection{Statistical analysis}

The data from the above experiments were statistically analyzed using Microsoft Excel. The statistical analyses included relationships between a decrease in crop yield and the amount of pollutants in the tissues of crops and exposed doses of pollutants. When the correlation coefficient $r$ is a positive value, a positive correlation relationship can be shown; if $r$ is a negative value, a negative correlation relationship can be shown. When the significance level $p<0.01$, there is a significant correlation relationship; when $p<0.005$, the correlation relationship is very significant.

\section{Results}

2.1 Dominant action of pollutant concentrations and their combinations

Many related results have shown that crop production responded to agricultural pollution by inhibition, less productivity or serious "zero" yield ${ }^{[7,18]}$. This study had the consistent results, in that the yield of wheat (Triticum aestivum) was decreased to different extents under the stress of combined acetochlor and $\mathrm{Cu}$. With a low concentration of copper $(30 \mathrm{mg} / \mathrm{kg})$, the significant positive linear correlation relationship can be expressed by the following equation:

$$
\begin{gathered}
Y_{1}=14.41 X_{\text {cae }}+122.66 \\
(r=0.524, n=28, p<0.005),
\end{gathered}
$$

where $Y_{1}$ is the yield of wheat, $X_{\text {cae }}$ is the concentration of the added acetochlor $(\mathrm{mg} / \mathrm{kg})$. It is evident that when copper concentrations were low, the interaction between these two pollutants inhibited the toxicity of acetochlor, and low $\mathrm{Cu}$ could stimulate the growth and development of wheat; the yield, therefore, showed an increasing trend. When copper was at the medium level $(90 \mathrm{mg} / \mathrm{kg})$, the correlation relationship can be expressed as follows:

$$
\begin{gathered}
Y_{1}=-26.86 X_{\text {ace }}^{2}+23.68 X_{\text {ace }}+116.87 \\
(r=-0.610, n=28, p<0.005) .
\end{gathered}
$$

The parabola with a down open indicated that the relationship was very complicated, with the antagonistic action being followed by synergetic effects. When the dose of copper became high $(150 \mathrm{mg} / \mathrm{kg})$, the negative correlation between the concentration of acetochlor and the yield was indicated by the following equation:

$$
\begin{gathered}
Y_{1}=-31.61 X_{\text {ace }}+122.14 \\
(r=-0.497, n=28, p<0.005) .
\end{gathered}
$$

In these three sets of experiments, ecotoxicological effects differed from each other as a result of the difference in the copper concentrations even though acetochlor was added at the same level, 0, 0.1, 0.3, 0.6, $0.9,1.2$, and $1.5 \mathrm{mg} / \mathrm{kg}$. In other words, in the case of effects on the productivity of wheat, concentration combination relationships of the two pollutants added to soils should be a determinant factor.

Similarly, effects of heavy metals such as $\mathrm{Cd}$ and $\mathrm{Zn}$ on output of rice were largely determined by their combination of concentrations (table 1). With a constant concentration of zinc, increasing the dose of $\mathrm{Cd}$ increased the output of rice, which significantly showed a positive correlation relationship. With zinc concentrations of 200 and $300 \mathrm{mg} / \mathrm{kg}$, the output of rice decreased with the increasing concentration of $\mathrm{Cd}$, namely a significantly negative relationship.

It was also indicated by the DGGE fingerprinting analysis of partial 16S rDNA gene segments from the contaminated soil that ecotoxicological effects at the molecular levels under combined pollution to a large 
Table 1 Relationships between added Cd-Zn concentration combinations and the yield of rice

\begin{tabular}{ccccc}
\hline Added $\mathrm{Zn} / \mathrm{mg} \cdot \mathrm{kg}^{-1}$ & Yield curve $(n=20)$ & Correlation coefficient $r$ & Correlativity & Significance level $p$ \\
\hline 100 & $Y_{2}=315.82+2.80 X_{\mathrm{Cd}}$ & 0.522 & Positive & 0.01 \\
200 & $Y_{2}=334.03-5.51 X_{\mathrm{Cd}}$ & 0.782 & Negative & $<0.005$ \\
300 & $Y_{2}=323.58-7.79 X_{\mathrm{Cd}}$ & 0.677 & Negative & $<0.005$ \\
\hline
\end{tabular}

degree were directly dependent on concentration combinations of pollutants added to the soil. When the exposed concentrations of combined acetochlor and $\mathrm{Cu}$ were 250 and $300 \mathrm{mg} / \mathrm{kg}$, respectively, 3 lucent specific bands appeared (fig. 1). In other words, there were possible mechanisms that the high concentration combination of the two pollutants could induce the gene mutation of soil microorganisms due to their strong acute toxicity, and/or specific microorganisms (e.g. endurable and degradable bacteria) which can be represented by the 3 specific bands were greatly increased and enriched under the stress of combined acetochlor and $\mathrm{Cu}$ at high concentrations ${ }^{[13,17]}$. When the exposed concentrations of combined acetochlor and $\mathrm{Cu}$ were only 100 and $100 \mathrm{mg} / \mathrm{kg}, 3$ specific bands did not appear. Moreover, there was no band under the stress of single acetochlor or $\mathrm{Cu}$. However, 3 brightness-decreasing specific bands appeared in 16S rDNA gene segments from the contaminated soil due to the long-term application of acetochlor and germicides containing $\mathrm{Cu}$. Thus, the low-dose and long-term exposure of combined acetochlor and $\mathrm{Cu}$ could result in the appearance of 3 specific bands due to a possible heritable mutation of microorganisms in order to accommodate this kind of environmental change. We expect that these interesting relevant mechanisms will be further explored in due course.

2.2 Directive effects of living organism species and ecosystem types

Exposed to single contaminants, acetochlor and $\mathrm{Cu}$, Eisenia foetida showed 0.307 and $118.70 \mathrm{mg} / \mathrm{kg}$ $\mathrm{LC}_{50}$. The $\mathrm{LC}_{50}$ of combined acetochlor and $\mathrm{Cu}$ reached $0.401 \mathrm{mg} / \mathrm{kg}$ after $48 \mathrm{~h}$ exposure. This demonstrated that combined contamination at a low level had a weak toxicity, namely antagonistic effects; when the $\mathrm{Cu}$ concentration was $90 \mathrm{mg} / \mathrm{kg}, 48 \mathrm{~h}$-exposure killed all the E. foetida. A conclusion can be reached that combined acetochlor and $\mathrm{Cu}$ at a high level promoted the toxicity, namely synergetic effects.

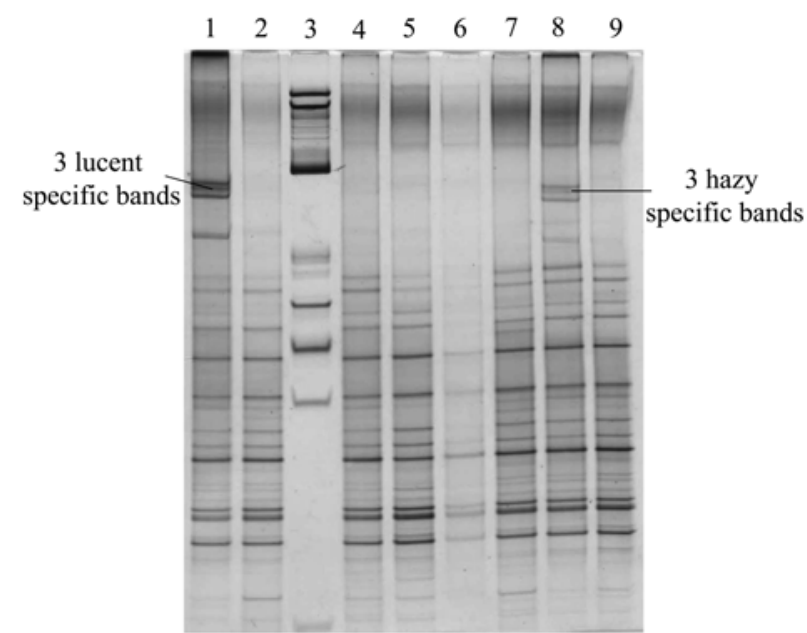

Fig. 1. DGGE analysis and imaging of 16S rDNA gene segments from contaminated soils. Lane 1, Treated by combined acetochlor ( 250 $\mathrm{mg} / \mathrm{kg})$ and $\mathrm{Cu}(300 \mathrm{mg} / \mathrm{kg}) ;$ lane 2 , treated by acetochlor $(100 \mathrm{mg} / \mathrm{kg})$ and $\mathrm{Cu}(100 \mathrm{mg} / \mathrm{kg}) ;$ lane 3, $\phi \mathrm{X} 174$; lane 4 , treated by single acetochlor $(100 \mathrm{mg} / \mathrm{kg})$; lane 5 , treated by single acetochlor $(250 \mathrm{mg} / \mathrm{kg})$; lane 6 , treated by single $\mathrm{Cu}(100 \mathrm{mg} / \mathrm{kg})$; lane 7 , treated by single $\mathrm{Cu}(300$ $\mathrm{mg} / \mathrm{kg}$ ); lane 8 , contaminated soil by agricultural activity; lane 9 , clean soil.

In contrast to E. foetida, Penaeus japonicus was more sensitive to single acetochlor contamination, which was evident through the lower $\mathrm{LC}_{50}, 0.128$ $\mathrm{mg} / \mathrm{L}$. Once copper was added, the toxicity to $P$. japonicus was promoted no matter whether copper concentration was low $(30 \mathrm{mg} / \mathrm{kg})$ or high $(90 \mathrm{mg} / \mathrm{kg})$. Further analyses, however, showed that acetochlor combined with low doses of copper strengthened the effects on P. japonicus, whereas acetochlor combined with high copper content affected the toxicity by adding their own single effects, namely additive effects. Therefore, in addition to the above-mentioned factors, the type of organisms also played an important role in their responses to poisonous compounds after interaction between pollutants in the environment, the socalled ecotoxicological effects of combined pollution.

The absorption and accumulation of $\mathrm{Cd}$ and $\mathrm{Zn}$ by potato (Solanum tuberosum), Chinese cabbage 
(Brassica Pekinensis Rupr), and wild amaranth (Amaranthus retroflexus) sampled from the Zhangshi Sewage-Irrigation area, the Qingchengzi Lead-Zinc Mining region, and the Shilihe agricultural area of Shenyang were analyzed (table 2). The former two regions were respectively polluted by irrigation with $\mathrm{Cd}$-waste water and mining activities. Compared with those from uncontaminated Shilihe area, these three crops sampled from contaminated districts accumulated cadmium to an obvious extent. In particular, in the case of Brassica Pekinensis Rupr there was a four-fold increase. As for zinc absorption, three kinds of plants from polluted areas demonstrated different trends with a significant increase in Solanum tuberosum and a noticeable decrease in Brassica Pekinensis Rupr, and Amaranthus retroflexus. Similarly, in the same control system, all crops from the Qingchengzi Lead-Zinc Mining region had a greater increase of 4.6-5.6 times in cadmium accumulations. With zinc uptake, Solanum tuberosum increased its extraction remarkably, whereas Brassica Pekinensis Rupr decreased it to some extent and Amaranthus retroflexus displayed a striking reduction, but a less severe slope in comparasion with that from the Zhangshi area. It can be concluded that combined cadmium and zinc mutually enhanced the toxicity to Solanum tuberosum, resulting from some accelerating absorption mechanism between them. Cadmium can inhibit $\mathrm{Zn}$ uptake in Brassica Pekinensis Rupr, and caused antagonistic action in Amaranthus retroflexu.

2.3 Impacts on living tissue targets attacked by pollutants

Under the stress of the combined pollution of acetochlor and $\mathrm{Cu}$, there existed a substantial difference in $\mathrm{Cu}$ absorption and accumulation between root systems and fronds of wheat. It was shown that at a low concentration of copper, $30 \mathrm{mg} / \mathrm{kg}$, there was a significant positive correlation relationship between the action of the root absorbing copper and the dose of acetochlor, according to the following equation:

$$
\begin{gathered}
Q_{\mathrm{Cu}}=6.22 C_{\mathrm{ace}}+21.62 \\
(\underline{r}=0.648, n=28, p<0.005),
\end{gathered}
$$

where $Q_{\mathrm{Cu}}$ is the amount of copper taken up by the root, $C_{\text {ace }}$ is the concentration added $(\mathrm{mg} / \mathrm{kg})$. It indicated that acetochlor can promote the biological absorption of copper by the underground parts, namely synergetic effects. Contrarily, the negative correlation relationship between the quantity of copper extracted in fronds and the added concentration of acetochlor in the soil can be expressed as follows:

$$
\begin{gathered}
Q_{\mathrm{Cu}}=-2.48 C_{\text {ace }}+8.57 \\
(r=-0.853, n=28, p<0.005) .
\end{gathered}
$$

In other words, acetochlor inhibited the $\mathrm{Cu}$ uptake by the so-called antagonistic effects.

Similarly, when copper was at the high level, 150 $\mathrm{mg} / \mathrm{kg}$, there was no noticeable correlation between the amount of $\mathrm{Cu}$ accumulated by roots and the added dose of acetochlor, with $r$ being only 0.049 . That is to say that the dose of acetochlor had no effect on the $\mathrm{Cu}$ uptake. Fronds, however, can accumulate increasing copper with an increment of acetochlor concentration, giving the regression equation:

$$
\begin{gathered}
Q_{\mathrm{Cu}}=8.64 C_{\mathrm{ace}}+20.57 \\
(r=0.736, n=28, p<0.005) .
\end{gathered}
$$

\begin{tabular}{|c|c|c|c|c|c|c|}
\hline \multirow{2}{*}{ Type of ecosystem } & \multicolumn{2}{|c|}{$\begin{array}{l}\text { Potato (Solanum tuberosum) } \\
(n=50)\end{array}$} & \multicolumn{2}{|c|}{$\begin{array}{l}\text { Chinese cabbage (Brassica } \\
\text { Pekinensis Rupr })(n=50)\end{array}$} & \multicolumn{2}{|c|}{$\begin{array}{l}\text { Wild amaranth (Amaranthus } \\
\text { retroflexus) }(n=50)\end{array}$} \\
\hline & $\mathrm{Cd} / \mu \mathrm{g} \cdot \mathrm{kg}^{-1}$ & $\mathrm{Zn} / \mathrm{mg} \cdot \mathrm{kg}^{-1}$ & $\mathrm{Cd} / \mu \mathrm{g} \cdot \mathrm{kg}^{-1}$ & $\mathrm{Zn} / \mathrm{mg} \cdot \mathrm{kg}^{-1}$ & $\mathrm{Cd} / \mu \mathrm{g} \cdot \mathrm{kg}^{-1}$ & $\mathrm{Zn} / \mathrm{mg} \cdot \mathrm{kg}^{-1}$ \\
\hline Zhangshi domain & 223.5 & 38.4 & 393.2 & 28.2 & 429.6 & 8.2 \\
\hline Qingchengzi region & 271.6 & 45.9 & 471.3 & 36.0 & 682.1 & 14.6 \\
\hline Shilihe area & 59.1 & 14.2 & 98.9 & 41.8 & 121.9 & 55.3 \\
\hline
\end{tabular}

Therefore, it can be concluded that at the high level, the added acetochlor can promote $\mathrm{Cu}$ accumulation in the fronds, namely showing synergetic effects.

Table 2 Cd-Zn accumulation by crops in different ecosystems 
Exposed to the combined pollution of $\mathrm{Cd}$ and $\mathrm{Zn}$, rice differentially absorbed $\mathrm{Zn}$ in different tissues as a result of the interaction between $\mathrm{Zn}$ and $\mathrm{Cd}$. When the concentration of $\mathrm{Zn}$ was $300 \mathrm{mg} / \mathrm{kg}$, increasing the dose of $\mathrm{Cd}$ increased the absorption of $\mathrm{Zn}$ in rice roots. The positive correlation relationship can be expressed by the following equation:

$$
\begin{gathered}
Q_{\mathrm{Zn}}=3.79 C_{\mathrm{Cd}}+150.00 \\
(r=0.522, n=28, p=0.01) .
\end{gathered}
$$

This suggested that the capability of extracting $\mathrm{Zn}$ by the root can be enhanced by $\mathrm{Cd}$. Instead, the negative correlation relationship between the amount of accumulated $\mathrm{Zn}$ in fronds and the level of added $\mathrm{Cd}$ can be expressed as follows:

$$
\begin{gathered}
Q_{\mathrm{Zn}}=-1.89 C_{\mathrm{Cd}}+60.71 \\
(r=-0.585, n=28, p<0.005) .
\end{gathered}
$$

It was obvious that the interaction between $\mathrm{Cd}$ and $\mathrm{Zn}$ showed an antagonistic action.

\section{Discussion}

Under stress from a single pollutant, harmful effects of the pollutant on organisms were basically determined by its physical and chemical properties ${ }^{[18]}$, especially the dose of pollutant affecting organisms ${ }^{[5,11]}$. Similarly, the concentration level played an essential role in the toxicological influences under the combined pollution of varieties of contaminants ${ }^{[7]}$. However, there has been a dispute about which factor, the concentrations themselves or the concentration combinations of pollutants, was key in this role. Results in this study supported the latter supposition. In other words, based on the yield and microbiological community changes, ecotoxicological effects of combined contamination were dependent on concentration combination relationships of pollutants in ecosystems despite other important factors, e.g. natural characteristics and single concentration levels. Also, experiments on the uptake by wheat of toxic elements validated this conclusion: acetochlor combined with a low dose of copper decreased $\mathrm{Cu}$ accumulation; at the high level of $\mathrm{Cu}$, the interaction between acetochlor and copper showed a synergetic action. The toxicity of combined acetochlor and $\mathrm{Cu}$ to E. foetida further proved the critical role of the concentration combination of pollutants by the demonstrated result that a high level of copper lowered the poisonousness of acetochlor, whereas a low level promoted the toxicity of acetochlor. Harmful impacts of combined acetochlor and copper on $P$. japonicus confirmed the conclusion when considering aqueous organisms.

Additionally, although exposed to the same pollution degree, different kinds of organisms responded to the interaction between pollutants with different trends. For example, under the stress of combined copper and acetochlor, the low dose of $\mathrm{Cu}$ can alleviate the toxicity of acetochlor to E. foetida. Contrarily, the low dose of $\mathrm{Cu}$ magnified the toxicity of acetochlor to $P$. japonicus. This kind of difference, of course, should contribute to interactions between in vivo constituents of organisms and pollutants. For this reason various ecotoxicological effects can be observed even if the organisms were exposed to the same circumstances of stress, hence bioaccumulation was influenced to a different extent despite of identical levels and types of contamination. Sometimes, in the same species, the different populations even showed different toxicological effects under the same kind of pollution $^{[19]}$.

Previous studies ${ }^{[2,18,20]}$ showed that many heavy metals, such as lead, copper and cadmium, tended to concentrate in the livers and kidneys of animals, and concentrated more strongly in the roots of plants than in the overground parts of plants. The mechanism underlying this intriguing distinction has remained unknown. This study, however, documented that heavy metals in different tissues of organisms can interact not only with the metals themselves but with the constituents of organisms. This result, although with differences between interactions, further demonstrated the different ecotoxicological effects, including the distinct capability of accumulating metals.

Acknowledgements This work was supported financially by the National Science Fund grant (Grant No. 20225722) for Distinguished Young Scholars, Key Basic Research Project (Grant No. G1999011808) of the National Development Planning, and Knowledge Innovation project (Grant No. KZCX2-SW-416) of the Chinese Academy of Sciences. 


\section{References}

1. Bliss, C. I.,. The toxicity of poisons applied jointly, Annual Applied Biology, 1939, 26: 585-615.

2. Kirkwood, R. C., Longley, A. J., Clean Technology and the Environment, London: Blackie Academic \& Professional, 1995.

3. Zhou, Q., Zhu, Y., Pollution monitoring of marine organisms grown in the Zhoushan Sea of China, Journal of Environmental Sciences, 1997, 9: 288-292.

4. Samet, J. M., What can we expect from epidemiologic studies of chemical mixtures? Toxicology, 1995, 105: 307-314.

5. Prakash, J., Nirmalakhandan, N., Sun, B. et al., Toxicity of binary mixtures of organic chemicals to microorganisms, Water Research, 1994, 30: 1459-1463.

6. Otitoloju, A. A., Evaluation of the joint-action toxicity of binary mixtures of heavy metals against the mangrove periwinkle Tympanotonus fuscatus var radula (L.), Ecotoxicology and Environmental Safety, 2002, 53: 404-415.

7. Zhou, Q., Ecology of Combined Pollution (in Chinese), Beijing: China Environmental Science Press, 1995.

8. Garte, S. J., Molecular Environmental Biology, London: Lewis Publishers, 1994.

9. Hughes, W. W., Essentials of Environmental Toxicology, Washington DC: Taylor \& Francis, 1996.

10. Sun, T., Zhou, Q., Li, P., Pollution Ecology (in Chinese), Beijing: Science Press, 2001.

11. Zhou, Q., Sun, T., Effects of chromium (VI) on extractability and plant uptake of fluorine in agricultural soils of Zhejiang Province, China, Water, Air, and Soil Pollution, 2002, 133: 145-160.

12. Feron, V. J., Groten, J. P., Toxicological evaluation of chemical mixtures, Food and Chemical Toxicology, 2002, 40: 825-839.
13. Martin-Laurent, F., Philippot, L., Hallet, S. et al., DNA extraction from soil: Old bias for new microbial diversity analysis methods, Applied and Environmental Microbiology, 2001, 67: 2354-2359.

14. Glovannoni, S. J., The polymerase chain reaction, in Nucleic Acid Techniques in Bacterial Systematics (eds. Stackebrandt, E., Goodfellow, M.), New York: John Wiley \& Sons, 1991, 177201.

15. $\Phi$ vreas, L., Forney, L., Daae, F. L. et al., Distribution of bacterioplankton in meromictic lake Saelevannet, as determined by denaturing gradient gel electrophoresis of PCR-amplified gene fragments coding for 16S rRNA, Applied and Environmental Microbiology, 1997, 63: 3367-3373.

16. Muyzer, G., Waal, E. C., Uitterlinden, A., Profiling of complex microbial populations using denaturing gradient gel electrophoresis analysis of polymerase chain reaction-amplified genes coding for 16S rRNA, Applied and Environmental Microbiology, 1993, 59: 695-700.

17. Bassam, B. J., Caetano-Anollés, G., Fast and sensitive silver staining of DNA in polyacrylamide gels, Annual Biochemistry, 1991, 196: 80-83.

18. Xiong, Z., Environmental Biology (in Chinese), Wuhan: Wuhan University Press, 2001.

19. Zhou, Q., Rainbow, P. S., Smith, B. D., Comparative study of the tolerance and accumulation of the trace metals zinc, copper and cadmium in three populations of the polychaete Nereis diversicolor, Journal of the Marine Biological Association of the United Kingdom, 2003, 83: 65-72.

20. Dong, Y. H., Gong, Z. M., Wang, H., Distribution of heavy metals in animals, Chinese Journal of Applied Ecology, 2002, 13: 213216. 